\title{
Exploration and Practice of Comprehensive Reform of Material Forming and Control Engineering Specialty
}

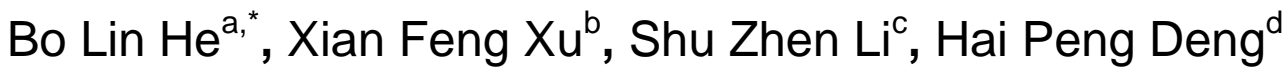

School of Mechanical \& Electrical Engineering, East China Jiaotong University, Nanchang, Jiangxi, 330013, China

ahebolin@163.com, bu-xianfeng@163.com, ${ }^{c} 13870955601 @ 163, c o m,{ }^{d} 1227871078 @ q q . c o m$

Keywords: Material forming and control engineering; Construction; Exploration; Comprehensive reform of specialty.

\begin{abstract}
Combined with the actual situation of material forming and control engineering in East China Jiaotong university, and starting from the aims, thinking and construction of comprehensive reform of specialty, this paper analyze the practice construction process of material forming and control engineering specialty. The construction of the specialty include enhancing the building of teaching staff, learning course, teaching materials, experimental base and engineering training base.
\end{abstract}

\section{Introduction}

Material forming and control engineering specialty in East China Jiaotong University developed from the original basis of metalworking teaching and research room in School of Mechanical and Electrical Engineering. The specialty began to recruit undergraduate students in 2000 and it was identified as the focusing specialty of professional development and construction program. In 2004, material forming and control engineering made great success in assessment of undergraduate bachelor degree education organized by the Bachelor Degree Education Department and Degree Office of Jiangxi province. It received consistent high praise from experts, and it was named as Jiangxi provincial brand specialty by that organization. We paid close attention to the quality of construction of the project. After four years of continuous efforts, we strengthened students the skills of model design and manufacturing. In 2008, it was named as Jiangxi provincial characteristic specialty. We achieved the success of declaring welding engineering direction in 2010. In 2013 June, Jiangxi Provincial Department of Education approved it as the annual pilot specialty of Jiangxi Province ordinary undergraduate colleges and universities comprehensive reform. Taking innovative training mode as a breakthrough, we have had a specialty whose students have strong practical ability and strong sense of innovation by promoting the reform of training mode, teaching staff, teaching material, teaching method and teaching management. We made the following exploration and practice during the process of comprehensive reform of the specialty.

\section{Make clear goal, construction idea and construction plan for comprehensive reform of the specialty}

The purpose of comprehensive reform should be formulated according to the requirements of national economy. So it can guide the different levels, types of universities to run school according to the orientation of its own [1]. The comprehensive reform of the specialty include building a reasonable curriculum system, optimizing the teaching content, teaching methods and means, strengthening the construction of teaching staff, strengthening the construction of teaching condition, carrying out special courses actively and constructing characteristic teaching materials[2-7]. Taking training plan, training target, training standard and basic requirements of material forming and control engineering specialty as the guide, combed with our school discipline advantage, we made the thought of professional development and talent cultivation clear, and strived to achieve the object of "solid foundation, fine professional, strong practice". We have created training features that students have 
employment ability and innovation ability. Constantly optimizing the curriculum, strengthening the construction of professional direction course group, strengthening the laboratory teaching construction, promoting comprehensive experiment project development, strengthening the function of the teaching reform and teaching plan adjustment; aiming at the forming advanced international theory, following the development trend of the manufacturing industry of the world, we enriched the knowledge of material molding specialty in our school. So we can improve the qualities of graduates, widening the employment and business coverage. With the regional economy development of construction and transportation industry in Jiangxi, based on continuous innovation mode and deepening teaching reform, material forming and control engineering became the leading specialty demonstration for other related professional reform of our school and the same type of other universities, which promoted the level of professional personnel training in colleges and universities.

"Material forming and control engineering" is a new professional education, first issued in 1998. because of the traditional old professional integration and diversity of professional direction, each university had big differences in training plan. According to advantage of educational resources in our school, following demand of the society, we gave priority to the direction of model design and manufacturing and increased a new direction of welding engineering later, which broaden employment channels for students. Follwing the idea of "solid foundation, fine professional, setting strong practice", we set up professional in accordance with the "mold design and manufacturing, welding engineering" two professional direction course group. Training plan is drawn up according to the development trend of the industry, closely following the industry needs.

Teaching plan is taken as the whole design scheme of the teaching. In the teaching plan we should not only consider cultivation of professional ability, but also consider the overall quality enhancement. In the construction of curriculum system, in order to strengthen the training of computer and English ability and ensure continuous line of its course and application, we encouraged students to obtain computer and English level certificates. During teaching process, we not required students to master the basic theory and professional knowledge only. what is more important is to let the students firstly learn to behave. Innovation talents of training system is shown in Figure. 1

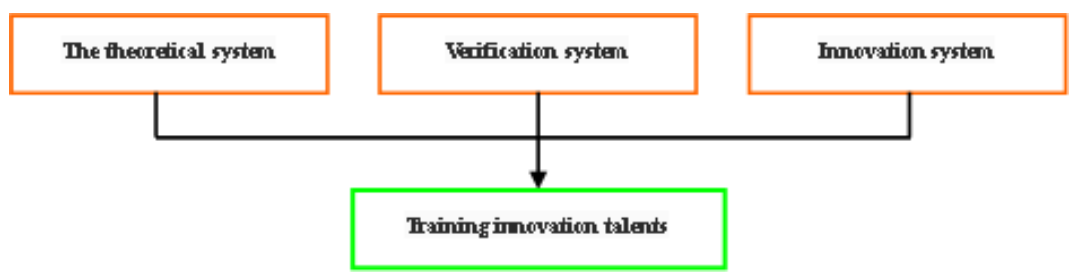

Figure. 1 Innovation talents of training system

In addition to basic course of social sciences and public engineering, the professional knowledge system consists of the following three main continous lines:(1)The "English language"; (2)The"Mold design and manufacturing, mechanical engineering"; (3)The "Computer technology and application (CAD/CAM/CAE, etc.)" .

With the development of society and the progress of technology, the material forming technology has became the backbone of modern manufacturing industry, especially for green manufacturing. The knowledge module of "material molding computer simulation", "agile manufacturing and virtual manufacturing", "reverse engineering and rapid prototyping manufacturing", and "CAD/CAM/CAE" are needed in modern molding industry. Those should be incorporated into the backbone of the professional courses and it will strengthen the practice teaching, highlightening the characteristics of talents education.

\section{Construction of teaching staff}

Construction of teaching staff is a key part of characteristic specialty construction $[8,9]$. Based on the original teaching staff, we drawn into talent teachers; at the same time, we paid attention to raising the 
existing teachers' teaching level and scientific research ability. With the "coming in, going out" approach, we encouraged teachers to actively participate in domestic and international academic conferences to raise the visibility of the professional at home and abroad.

In the aspect of teaching, young teachers have improved the teaching level with the help of rich teaching experience of senior teachers; in the aspect of scientific research, scientific research level of the subject improveed greatly by the forward-looking planning of academic leaders.

This subject possesses strong teaching team and reasonable structure. There are 17 professional course teachers, including ten with doctoral degree, five with master degree, two PhD students, six professors, eight associate professors, five lecturers, and one assistant professor. One teacher was named as the famous teachers in Jiangxi Province and one teacher was named as high level teachers of the university, and three were rated as grade two teachers of the university.

\section{Constuction of curriculum system}

In the process of promoting comprehensive reform construction, standing in the forefront of materials processing, we should promote the reform of teaching contents and curriculum system with international vision. On the one hand, closely tracking the forefront of science and strengthening the cultivation of comprehensive quality are needed. Renewing teaching content and gradually increaseing the comprehensiveness of experiment are also important. On the other hand, adhering to the guide of "teaching and scientific research promote each other [10]", the professional teachers improvemed teaching qualityby combing teaching and scientific research. In recent years, teachers in our specialty obtained a number of national and provincial and ministerial level scientific research. The third is to make more efforts on the construction of excellent courses. Based on school ranked course "foundation of engineering materials and machinery manufacturing", "mold design" and "plastic processing theory", we actively declared those courses as provincial excellent curriculum. The active integration of teaching resources and actively promoting the construction of other courses was made to create provincial university level courses.

\section{Constuction of teaching materials}

Materials used by the specialty are mostly national or provincial excellent teaching materials, we timely updated the knoeledge according to the speed of renewing knowledge, making notes newer than the textbook and textbook newer than handouts courseware. The construction of teaching material is an important factor in the development of the discipline. Teaching materials should be able to cultivate and improve capability of comprehensive reflection. According to the characteristics of teaching, backbone teachers in our teaching and research section actively cooperateed with other universities and colleges, and widely absorbed the practical experience of the engineers, jointly writing various materials for material forming and control engineering. In the process of compiling teaching materials, we took the application of knowledge and ability of training as the main line, meanwhile the application of new knowledge, new materials, new technology and new equipment in engineering is taken into account. Currently five books have been compiled. And now we are compiling bilingual teaching materials of "Mechanical Engineering Materials" and guide book of "engineering materials and machinery manufacturing experiment ".

\section{Constuction of practice and engineering training base}

Original laboratory area of the major is less than $200 \mathrm{~m}^{2}$. After several years of construction, the existing laboratory area is $1048 \mathrm{~m}^{2}$, with total assets more than 15 million yuan. In the aspect of laboratory equipment, material forming laboratory possess scanning electron microscope, electronic tensile testing machine, fatigue testing machine, optical microscope, aluminum alloy die-casting machine, magnesium alloy die casting machine, high temperature vacuum brazing furnace, vacuum 
sintering furnace, wear test machine and other advanced experimental equipment. The experimental equipment fully guarantee that the major can offer a variety of opening and innovative experiments.

The professional experiment teaching staff consists of two groups. The full-time experiment teaching staff include teachers and laboratory. There are one senior engineer, five engineers and lecturers, one senior technical workers. Four of them are with bachelor degree or above and two people with college degree. After years of experimental teaching, these experimental personnel has proved that they can cooperate with professional staff room to open professional comprehensive and innovative experiments.

After years efforts of the school leadership and the professional teachers, the professional has established stable practice base on campus. these bases can fully meet the student curriculum design, graduation practice and design teaching needs. So far this specialty has opened practice base of "Phoenix Optical Company Limited", "Changhe Automobile Group Co., Ltd", "Zhejiang saihao mould Co. Ltd", "Tongling Sanjia mould company", "Luoyang mining machinery factory" .

\section{Teaching reform and innovation}

We paid full attention to teaching reform and research work. Reform and research results was used to promote the teaching work, comprehensively improving teaching level and the quality of talent cultivation.

In the bilingual teaching course of "engineering materials and heat treatment", some content is abstract and boring, such as the contents of basic theory of metal. It is easy to make students weariness. Many kinds of teaching method (heuristic type, import type, question and answer type, case type and so on) are used to maximize learning interest of student.We made bilingual teaching equiped with multimedia courseware, illustration, and animation. Chinese and English vocabulary is given to students before each class, lightening the students' burden. In the new curriculum teaching, we used heuristic teaching method, enriching the teaching content. For instance, the heat treatment of metal part content is monotonous, but it is more closely linked with the actual. In the teaching of the part, the use of multimedia courseware deepen the perceptual knowledge of students, improving the students' learning interest and effect. In addition, we went to the factory for heat treatment video. Real situation of the heat treatment process in the factory was shown in the classroom, helping students master the basic theory and practical operation of heat treatment in short time. The teaching achievement in 2013 won the second prize teaching achievements in Jiangxi province.

After tracking students' metalworking practice process for long time, we undertook adjustment to the engineering training content related to the course, increasing welding mechanism innovation module. Welding module added $\mathrm{CO}_{2}$ gas protection welding, argon arc welding, laser welding and other welding new method. Casting module added a new method of EPC and other special casting. We formed a new practice teaching mode in the modern engineering training center under the framework of metalworking.

We implemented network management for opening experimental teaching, such as: online booking opening engineering training project, downloading open engineering training application data, online Q \& A and so on; the basic center information was published online, such as introduction, the general situation of guidance teachers in the engineering training center, teaching achievements, the basic situation of the engineering training center, teaching arrangement etc.

Stage of undergraduate graduation design was difficult to manage in early years. Graduation design quality was not high. We went through years of research, finding out a set of solutions to problems, and prepare to declare the research project of teaching reform in Jiangxi province. We mainly did the following work: to cultivate students' access to documents and technical writing ability in the teaching of specialized courses; establish a strict graduation design topic review system and report system; strengthen the management system, establish monitoring mechanism. After the popularization and application of the experience in recent years, The quality of graduation design is improved than before. 


\section{Conclusion}

Starting from the objectives, ideas and construction scheme of the professional comprehensive reform, through the construction of teachers team, the construction of teaching materials, the construction of laboratory and engineering training base, the construction of campus practice base, teaching reform, the building of teaching staff with high quality, we build the cultivation system with distinct characteristics. In the future we will also continue to deepen teaching reform, strengthening the connotation construction of education quality, strengthening the construction of teaching staff, improving the level of scientific research, strengthening the construction of practice base of laboratory, emphasising on constructing two to three off campus internship bases, improving the quality of production practice for students. Optimizing the conditions for running schools and promoting comprehensive development of material forming and control engineering specialty made great contribution for the country and social development for Jiangxi province.

\section{Acknowledgment}

The research is supported by the pilot project of professional comprehensive reform of general undergraduate colleges and universities in Jiangxi province(No.2013 GZC0028).

\section{References}

[1] Wang Qinruo, Zhang Yun, Chen Wei, et al. Construction of National Characteristic Specialty for Automation Specialty[J]. Journal of Guangdong University of Technology(Social Sciences Edition), 2008, (8) S1: 192-193.(in Chinese)

[2] Guo Tiantai , Li Dongsheng, Xie Dailiang, et al. Extraction and Construction of a State-level Feature Specialty-Measurement \& Cont rol Technology and Instrumentation[J]. High Education of Chemical Industry. 2008, 12(6):7-10. (in Chinese)

[3] Li Yuanyuan. Enhance the Construction of Characteristic Specialty and Increase the Quality of personnel training[J]. China Higher Education, 2008, 17 (1):25-27. (in Chinese)

[4] Shen Shaohua, Huang Niandong, Hu Zhongyu, et al. "Chemical Technical Economy" Curriculum Reform and Construction under the Background of Comprehensive Reform of Specialty[J]. Guangdong Chemical Industry.2014, 41(8):166-167(in Chinese)

[5] Mao Guo bing, Zhang Guangsheng, Liu Qi. Reform and exploration for links of experimental teaching of material shaping and control engineering specialty[J]. Experimental Technology and Management,2010, 21(6):140-142. (in Chinese)

[6] Xu Feng, Liu Yan, Feng Xiaoming. Reform Study on Innovation Talent Culture Pattern for Material Processing and Controlling Engineering[J]. Foundry Technology, 2013, 34(4):471-473 (in Chinese)

[7] Liu Weiqian, Luo Yun, Li Tielin. Initial Exploration of the Reform about Talents Training Target and Mode in the Major of Material Forming and Control Engineering [J]. Journal of Hunan Institute of Science and Technology (Natural Sciences), 2014, 26(1):93-94 (in Chinese)

[8] Zhang Fengden, Wang Zhengxiang. Develope Our Characteristic Specialty over Guaranteeing Common Base[J]. Journal of University of Shanghai for Science and Technology(Social Sciences), 2006, 28 (2) : 32-36. (in Chinese)

[9] Wang Yongsheng, Qu Bo, Liu Tuo. Construction of Characteristic Specialty and innovation of personnel training[J]. China Higher Education. 2008(15、16):15-17. (in Chinese) 
[10] Li Zhonghai, ZHONG Haiyan, Xiang Chunjie.Construction of National Characteristic Specialty for Food Science and Eng ineering[J]. JOURNAL OF CENTRAL SOUTH UNIVERSITY OF FORESTRY \& TECHNOLOGY (Social Sciences), 2009, 6(3):175-177. (in Chinese) 